\title{
A Perspective on Counting Catalytic Active Sites and Rates of Reaction Using X-Ray Spectroscopy
}

\author{
S. A. Kondrat ${ }^{1}$ · J. A. van Bokhoven ${ }^{2}$
}

Published online: 13 October 2018

(c) The Author(s) 2018

\begin{abstract}
Identification of active sites and phases in heterogeneous catalysts and the understanding of the reaction mechanism remain highly challenging. In most catalysts, the existence of a multitude of surface species, which are dynamic in relation to reaction conditions, presents a challenge of distinguishing those that are involved in the catalytic cycle from those which are spectators. The emergence of the field of single-site catalysts potentially eliminates these issues, although it can be argued that these systems remain dynamic and that multiple speciation, each a candidate for the active site, often remains a consideration. A perspective on how X-ray spectroscopy and characterization tools in general, can be used to correlate the number of active sites and the rate of their formation, in single-site and redox catalyst systems, is presented. The importance of observing proportionality between spectra features and the reaction rate, to differentiate between active sites and spectator species is discussed. Performing characterisation under catalyticly relevant conditions on structures that are demonstrably representative of actual catalysts is essential.
\end{abstract}

Keywords Active-site $\cdot$ Spectator species $\cdot$ Single-site $\cdot$ X-ray spectroscopy $\cdot$ Operando $\cdot$ Transient experiments

\section{Introduction}

Catalysis, the process of enhancing the rate of a reaction using a material that is unchanged chemically after each reaction cycle, is a scientific field with significant practical application and a source of continued ground-breaking fundamental research. Catalysis is commonly used in the chemical industry and in energy conversion processes. However, the fundamental understanding of the catalytic process is much less developed. Reaction kinetics is fundamental to the study of catalysis; to properly evaluate the properties of a catalyst, rate enhancements are correlated with the number of specific active components, the active sites, within a catalyst. Understanding of the catalytic cycle and identification of the evolution of the catalytically active site throughout

S. A. Kondrat

S.Kondrat@lboro.ac.uk

$\triangle$ J. A. van Bokhoven

Jeroen.vanbokhoven@chem.ethz.ch

1 Department of Chemistry, Loughborough University, Loughborough, Leicestershire LE11 3TU, UK

2 Institute for Chemical and Bioengineering, ETH Zurich, 8093 Zurich, Switzerland the cycle, is of great importance to achieve this fundamental understanding. While identification of the active component and the catalytic cycle is conventionally considered to be relatively simple for homogeneous catalysis, it has long been realised to be far more challenging in heterogeneous catalyst systems.

The concept, determined by Taylor in 1925 [1], that ratedetermining catalytic reaction steps occur on certain surface sites (termed as active sites) and not over the entire solid catalyst surface is key to understanding the complexity of studying heterogeneous catalysts. It is well accepted that even relatively simple surfaces, such as that of a of bodycentred cubic metal, are diverse with an array of terraces, steps and defects. Even this simple metal catalyst has multiple chemical species [2]. Within this plethora of structural sites, some or all may contribute to a catalytic reaction, with potentially different activities for each site. Consequently, a significant proportion of a catalyst may be a spectator, with no involvement in the catalytic reaction. Several reviews are dedicated to the discussion of active sites in heterogeneous catalysis and readers are directed to these for a comprehensive discussion [3-5]. A clear issue in the study of heterogeneous catalysis is the determination of what the structure of the active site is, an obviously essential requirement to then 
understanding how many there are and what its turnover rate is.

A further complication is that the assumption of the active site being a static entity is often far from true, with it being dynamic and sometimes transient in nature [6]. The structure of catalyst phases and surfaces are influenced by the reaction conditions, such as temperature and pressure that determine the coverage of reactants, intermediates and products. Examples of such structural changes are now numerous, with notable examples being changes in $\mathrm{Cu}-\mathrm{ZnO}$ structures and interfaces during methanol synthesis (Fig. 1) [7-9] and surface structural changes of platinum in carbon monoxide oxidation $[10,11]$. On the molecular level, some catalyst species in a catalytic cycle, are short-lived with subsequent steps of the cycle occurring at a much faster rate [12]. Identification of such species remains challenging as they are short-lived within the catalytic cycle and do not even exist in an ex situ experiment. Their short-lived nature makes their identification under actual catalytic conditions difficult, if not impossible.

To tackle the significant complexity of dynamic catalyst structures and intermediates, the scientific community has become increasingly reliant on operando characterisation [13]. Specifically, this is defined as the monitoring of catalyst structure, speciation and reaction intermediates while simultaneously performing, and crucially monitoring, a catalytic reaction. Introduction of the term operando has product the much-needed focus on measuring catalysts under catalytic relevant conditions and while the catalyst is

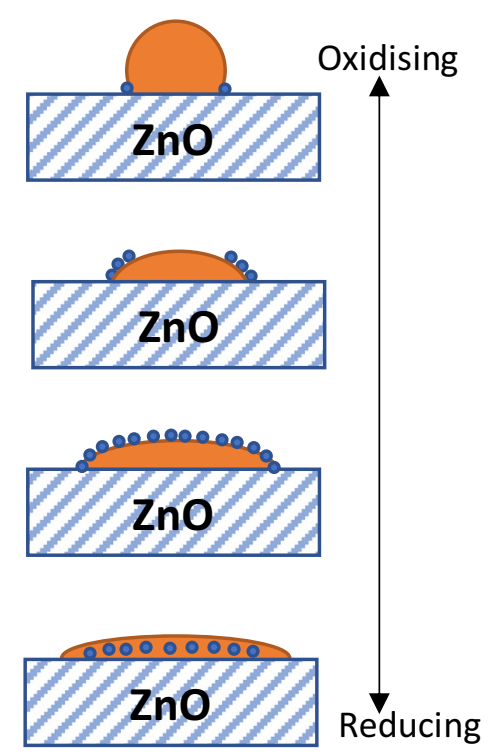

Fig. 1 Scheme of the wetting of a copper nanoparticle on a zinc oxide support, under different oxidising potentials, as an example of how reaction conditions change catalyst micro-structure. Blue dotes signify reduced zinc, orange is reduced copper. Reproduce with permission from ref. [9] performing. Many characterisation techniques can be performed in operando studies, with common examples being infrared and Raman spectroscopy, UV-Vis spectroscopy, $\mathrm{X}$-ray diffraction and X-ray emission/absorption (XES/XAS) spectroscopy. Given the significant scope of this research field, we direct the reader interested in an in detail overview of such characterisation methodologies, to the following review articles on operando characterisation of catalysts [14-17]. However to summarise, specific and well-thought out operando characterisation experiments provide valuable insights to heterogeneous catalyst structures and surface intermediates under operating conditions. The relevance of such observations to catalytic performance can then be interpreted by relating observed species with recorded catalytic performance. Yet, several challenges, difficulties and even incorrect interpretation of active sites/reaction intermediates are prevalent from operando studies.

An aspect of operando characterisation of catalysts recognised as potentially problematic, is the correlation of observations made using a dedicated reactor for operando characterisation with those from catalytic reactors optimised for kinetic studies or industrial reaction conditions. Often, in the former type of cell, reactions are performed far from realistic conditions, resulting in misrepresentation of surface coverages or reactants and importantly products. An example of the importance of correctly considering realistic reaction conditions is demonstrated by Fischer et al. who simulated relevant partial pressures of water on Co catalyst oxidation in Fischer-Tropsch synthesis [18]. Further the importance of "kinetically-appropriate", that is sufficient control of reactant mixing, dead-volumes and residence times in operando reactors must be considered $[19,20]$.

The challenge of catalyst speciation and being able to identify kinetically relevant active sites and reaction intermediates persists with operando characterisation studies. An example of the challenge is illustrated by operando diffuse reflectance infrared spectroscopy of reaction intermediates in the water-gas shift reaction. The presence of high surface coverage of formate species has been suggested as evidence of being a reaction intermediate in the adsorptivetype mechanism [21, 22]. However, detailed work by Burch et al. and Tibiletti et al. has suggested that in many cases, formate exists as a spectator species or it is involved only in a minor reaction pathway [23, 24]. From the perspective of potential active site speciation, debates on the catalytic relevance of isomorphically substituted metals in zeolites or extra-framework species being the active sites active site is another example [25, 26].

At this point it is worth stepping back from the use of catalyst characterisation, ex situ or operando, to elucidate catalyst cycles and active sites, and to be reminded of the importance of kinetic modelling in determining reaction mechanisms and, therefore, information on the active site. 
Prominent work on fitting micro-kinetic studies into a global kinetic model to validate proposed mechanisms, shows the potential of kinetic modelling [27-29]. Bond provides eloquent warnings for the catalyst community to place greater emphasis on kinetic modelling of reactivity data to formulate, test and validate surface mediated catalytic reactions [30]. Specifically, Bond concludes that "comprehensive measurement of kinetics is the only reliable way of accessing the transition state, and any mechanism derived from other information must be regarded as tentative until confirmed by kinetics, and any that is not in harmony with them is unacceptable".

For a comprehensive understanding of catalytic active sites and reaction mechanisms, observations from operando characterisation studies should be correlated with and informed by kinetic studies of the reaction. If catalytically active sites can be monitored by an operando characterisation study, then the observed reaction rate should be correlated with the number of these observed sites. Further, the rate of formation or decay of observed active species and/or reaction intermediates can be monitored, enabling them to be compared with the global rate of the catalytic reaction [12, 31, 32]. Comparisons of such rates help identifying which sites are involved in the reaction mechanism and which are not and thus spectators. Such examples can be found in the literature, prominent amongst these is the isotopic transient kinetic studies with infrared spectroscopy [23].

Operando techniques can be developed for counting and monitoring the rate of catalytic species. One technique that is particularly powerful for elucidating inorganic catalyst active sites in an element-specific and quantitative manner is XES/XAS spectroscopy [33], with the ability to focus on specific elements of interest under conditions amenable for operando study. Its potential limitation being that it is an averaging technique with sometimes significant reliance on modelling of data, resulting in criterium of interpretation being open to bias. However, such pitfalls and limitations can and should be mediated by proper correlation of proposed active sites with kinetic data from the reaction. The remainder of this perspectives article will focus on using $\mathrm{X}$-ray spectroscopy to identify, count and determine the rate of catalytic active sites.

\section{Single-Site Catalysts; Association of Observable Sites and Reaction Kinetics}

An alternative approach to resolving the issue of active site speciation is the preparation of single-site catalysts [34]. The concept is that such catalysts comprise of a single type of active site that is identically chemically and spatially replicated across the catalyst. A classic example of such a catalyst is a zeolite, which is a crystalline alumina silicate, in which the protons are associated with tetrahedrally coordinated aluminium atoms within the crystalline framework $[35,36]$. In zeolite H-ZSM-5, the reaction rate for hexane cracking is strictly proportional to the number of framework aluminium sites [36]. The field has many more diverse examples of proposed single-site catalysts, including isomorphic substituted metals in zeotype frameworks, tethered molecular catalysts (analogous to homogeneous catalysts) and the so-called single atom catalyst (adatoms of transition/noble metals on a support structure). The following reviews are recommended for those interested in a fuller overview of the topic of single-site catalysts [37-41]. Overarching all of these examples and permutations is the advantage of simplifying the determination of the reaction mechanism and catalytic turnover in regard to the single type of active site.

Characterisation of such single-site species has been dominated by transition electron microscopy, which clearly discriminates and identifies the isolated nature of single or small clusters of adatoms [42]. However, highly important aspects of these sites are not easily determined by microscopy, such as the electronic structure and oxidation state, the nature of the co-ordinated ligand species and the support interactions. X-ray spectroscopy can provide information on these important aspects of the active site and can be used in combination with microscopy and other techniques, such as DRIFTS [37].

It becomes evident, that the concept and reality of singlesite catalysis are very difficult to completely align. Che et al. highlight the potential for multiple speciation, in terms of nuclearity, oxidation states and support interactions, in socalled single-site catalysts (an example of silanol groups in amorphous silica is shown in Fig. 2) [43]. The simple observation of isolated atoms cannot be used to identify the unique existence of single-site catalysts, as different chemical species can still co-exist within this context. Very precise and thorough catalyst preparation by Hoffman et al. has shown that such heterogeneity in speciation can be overcome in specific cases [44], although this is far from common in most reported single-site catalysts. Mirroring earlier discussions about active sites, we must also seriously consider that single-site species are no less dynamic or prone to change during reaction than more conventional catalysts. Such species can well change oxidation state and local coordination geometry under operation. Further to this, agglomeration and the formation of clusters and nanoparticles has been reported during reaction, complicating assertions of singlesite catalysis [45-48]. Nuclearity, while controlled prior to reaction can change during reaction, undoing all the proposed benefits of single-site catalysts for understanding mechanism and catalytic turnover. Notwithstanding these complexities, examples exist which show how single site catalysts contribute to the fundamental understanding of the 
Fig. 2 Model of the surface of amorphous silica showing - $(\mathrm{Si}-$ $\mathrm{O}-)_{\mathrm{n}} \mathrm{n}=3-8$ cycles and various $\mathrm{Si}-\mathrm{OH}$ groups (I-III). The figure clearly illustrates different speciation of isolated $\mathrm{Si}$ atoms. Reproduced with permission from ref. [43]

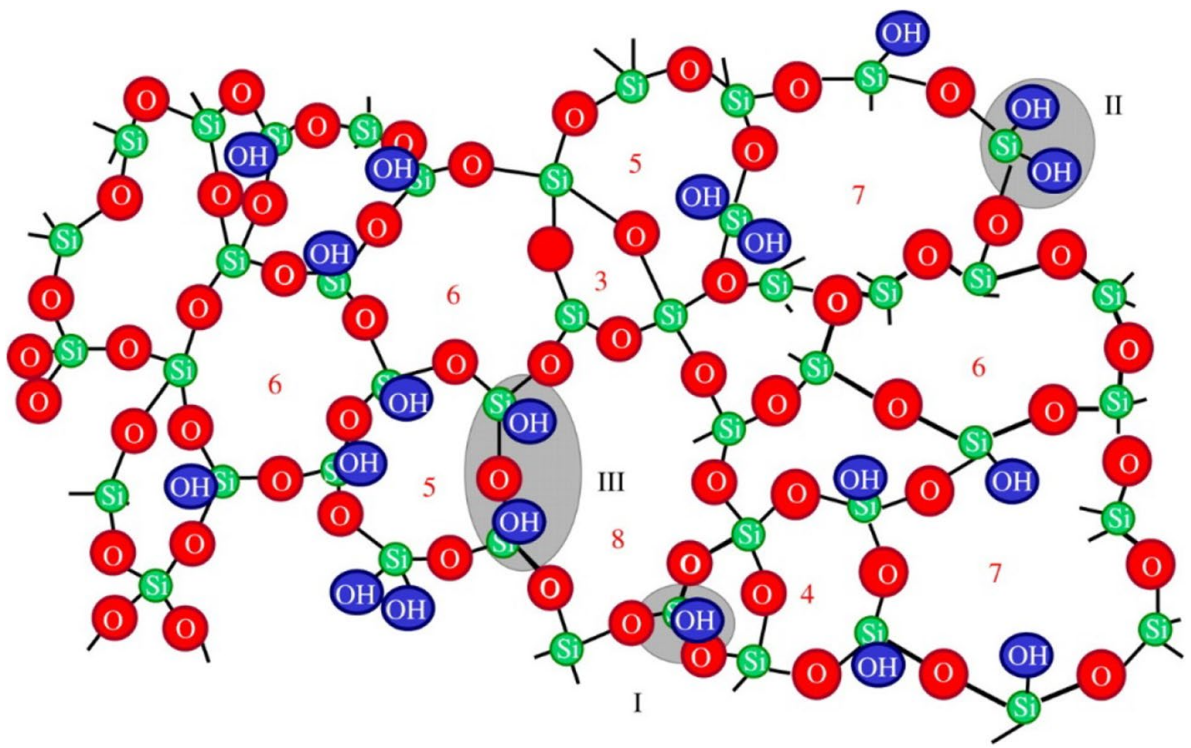

concept of the catalytically active site and the catalytic process in general [38, 40, 41].

\section{When Operando Is a Necessity and When It Fails}

Below, we highlight two successful strategies to identify the structure of the active sites. They are based on (i) determining the strict proportionality between the amount of a specific site with catalytic activity and (ii) quantifying the rate of conversion of a specific site after a rapid change in conditions and comparing this to the rate of the steady state conversion.

The Brønsted acid site in zeolites is a typical example of the first case (vide supra). As this site is associated with the tetrahedrally coordinated framework aluminium atom, which can be determined by ${ }^{27} \mathrm{Al}$ MAS NMR, in situ and operando measurements are not needed. When the active sites only form under reaction conditions, such as the gold active sites in acetylene hydrochlorination to vinyl chloride monomer (VMC), an operando measurement is needed to be able to quantify the number of sites (vide infra). A recent operando XAS study of $\mathrm{AuCl}_{\mathrm{x}} / \mathrm{C}$ catalysts (where $\mathrm{x}$ varies throughout the reaction) for acetylene hydrochlorination to VMC, will be used as an example of how such single-sites can be measured and be proportionately correlated with reaction rate $[49,50]$.

The second case is more complex, and an example is the Mars-van-Krevelen mechanism, which is well-established in catalysis. The characteristic feature of this mechanism is that some products of the reaction leave the solid catalysts' surface with one or more constituents of the catalysts' lattice [51]. The oxidation of carbon monoxide over $\mathrm{Pt} / \mathrm{CeO}_{2}$ is a typical example: oxygen from the lattice ends up in carbon dioxide and the resulting vacancy is filled by oxygen from the gas phase (Fig. 3). The formation of each vacancy is accompanied by reduction of two Ce(IV) ions into Ce(III) ones. Because re-oxidation of $\mathrm{Ce}$ (III) is much faster than reduction of $\mathrm{Ce}(\mathrm{IV})$ (vide infra), the reactive cerium atoms at the metal support interface have oxidation state + IV under reaction conditions and cannot be distinguished from any of the other cerium atoms in the ceria lattice. Measuring the structure of cerium in an operando experiment will not identify the active cerium atoms, because the active ones as well as those of the lattice will have oxidation state +IV. A transient experiment $[23,52]$, which determines the rates of

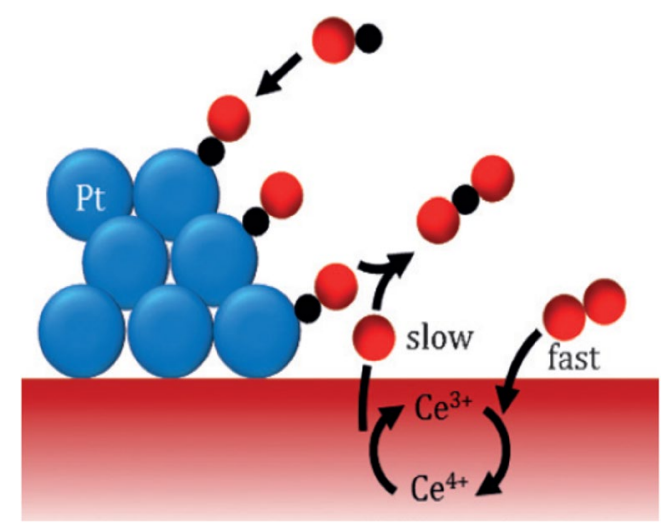

Fig. 3 Oxygen from the ceria support is reacted to carbon monoxide that is adsorbed on platinum; two cerium atoms are thereby reduced from $\mathrm{Ce}(\mathrm{IV})$ to $\mathrm{Ce}(\mathrm{III})$. Because re-oxidation is faster than the reduction, under reactive conditions (carbon monoxide and oxygen), all cerium atoms have oxidation state +IV. Reproduced with permission from Kopelent et al. [12] 
cerium reduction and re-oxidation enables identifying the role of the $\mathrm{Ce}(\mathrm{III})$ ion in the reaction mechanism (vide infra).

\section{Counting Gold Chloride Active Sites for Acetylene Hydrochlorination}

Acetylene hydrochlorination represents one of two major industrial chemical routes to VCM, the monomer of poly vinyl chloride, which is one of the most used thermoplastics globally [53]. The traditional catalyst for the process is mercuric chloride supported on carbon, but its high vapour pressure under reaction conditions $\left(180-220^{\circ} \mathrm{C}\right)$ and toxicity results in a drive to find an alternative catalyst [54-57]. A number of supported metal chlorides where screened for the reaction [58], with a significant advance coming from Hutchings prediction, based on the correlation of previously reported standard electrode potentials of materials and their catalytic performance, that gold would be highly active [59]. Subsequently, this prediction was found to be correct [60], resulting in a sustained research program by Hutchings, others and industry into gold catalysed acetylene hydrochlorination. The reader is directed to the following reviews on this research and its development to commercialisation [61-63].

To provide context, we will briefly discuss the background and evolution of thought around the active site for $\mathrm{Au} / \mathrm{C}$ acetylene hydrochlorination; a fuller discussion can be found in the following perspective paper [50]. Given the correlation with the standard electrode potential and therefore a two-electron process, it is generally agreed that cationic gold is important in the reaction mechanism. Experimental evidence of cationic gold species, in fresh (i. e. prior to catalytic testing) and post reaction samples, has been found with ${ }^{197} \mathrm{Au}$ Mössbauer [64], X-ray photoelectron spectroscopy [65] and temperature programmed reduction [66]. While the presence of cationic $\mathrm{Au}(\mathrm{III})$ was clear from these studies, conflicting and unclear evidence for the presence of $\mathrm{Au}(0)$ and $\mathrm{Au}(\mathrm{I})$ was reported. The significant issue being an over-representation of $\mathrm{Au}(0)$, due to photoreduction and the recoilless fraction differences between species $[50,67]$. No operando characterisation study of $\mathrm{Au} / \mathrm{C}$ catalysts had been reported. Given the presence of halide reactants (hydrochloric acid) at high temperature, it could be anticipated that gold speciation would change dramatically under operating conditions.

The first ever reported operando XAS study of Au/C catalysed acetylene hydrochlorination was reported by Malta et al. [49]. A range of $1 \mathrm{wt} \% \mathrm{Au} / \mathrm{C}$ catalysts prepared using various preparation methods, known to produce quite different activity profiles for acetylene hydrochlorination, were studied. Reaction conditions of $200{ }^{\circ} \mathrm{C}$ with a reactant gas composition of $2.36 \%$ acetylene and $2.40 \%$ hydrochloric acid balanced with argon were used throughout. $\mathrm{Au}_{3}$-edge
XAS was performed in transmission, across a fixed catalyst bed, while simultaneously monitoring reaction products by mass spectrometry. Significant detail on catalyst structure was elucidated both from the X-ray absorption near edge structure (XANES) and extended X-ray absorption fine structure (EXAFS).

The first key observation was that the gold speciation in the active catalysts, prepared using excess hydrochloric acid and nitric acid in the gold precursor solution or by using an $\mathrm{Au}-\mathrm{S}_{2} \mathrm{O}_{3}$ complex, comprised of no measurable $\mathrm{Au}(0)$ nanoparticles prior to reaction. Evidence for this was from a complete lack of $\mathrm{Au}-\mathrm{Au}$ distances from EXAFS, no metallic features in the XANES and high resolution HAADF-STEM showing only isolated gold species (Fig. 4). The atomic dispersion of gold was retained on heating and throughout the entire 240 min reaction period during which operando $\mathrm{Au} \mathrm{L}_{3}$ XANES and EXAFS were recorded. Inactive catalysts were shown to comprise $\mathrm{Au}(0)$ nanoparticles, demonstrating the importance of the isolated gold species.

Further investigation of the nature of these isolated gold species relied on interpretation of the $\mathrm{Au}_{3}$-XANES, which is dominated by a white line feature associated with the $2 p_{3 / 2}$ to 5d transition [68]. The intensity of the normalised white line can be taken as a measure of $5 \mathrm{~d}$ band occupancy and therefore the oxidation state of the gold. Correlation of the observed normalised white line intensity to known $\mathrm{Au}(\mathrm{III})$ and $\mathrm{Au}(\mathrm{I})\left(\mathrm{KAuCl}_{4}\right.$ and $\left.\left[\mathrm{AuCl}_{2}\right]^{-}\right)[68]$ standards allowed for the oxidation state of the isolated gold species to be monitored throughout the reaction. Such methodology is complicated by ligand type and coordination, yet the strategy was suitable as; (a) no other conceivable chemical ligand other than chloride or acetylene analogues could be envisaged and (b) normalised white line height could be correlated well to the $\mathrm{Au}-\mathrm{Cl}$ coordination number from EXAFS at all reaction times.

In active catalysts prepared from hydrochloric acid and nitric acid solutions, while all gold existed as isolated cations, at least two species existed with different oxidation states $[\mathrm{Au}(\mathrm{I})$ and $\mathrm{Au}(\mathrm{III})]$. As the catalysts were heated to reaction temperature a notable global reduction to predominantly $\mathrm{Au}(\mathrm{I})$ chloride was observed. The absolute need of studying the system by operando spectroscopy became apparent on the introduction of reactant gases, with an almost instantaneous increase in gold white line being observed, indicating rapid oxidation of $\mathrm{Au}(\mathrm{I})$ to $\mathrm{Au}(\mathrm{III})$ chloride (Fig. 5a). As previously observed, the catalytic performance of these $\mathrm{Au} / \mathrm{C}$ catalysts prepared from chloride precursors in excess hydrochloric acid and nitric acid exhibited an induction period, with activity slowly climbing over a 160 min to a steady state VCM productivity. A key observation was that during this induction period the $\mathrm{Au} \mathrm{L}_{3}$ XANES showed a steady reduction of $\mathrm{Au}(\mathrm{III})$ back towards $\mathrm{Au}(\mathrm{I})$, suggesting that $\mathrm{Au}(\mathrm{I})$ species were important within 

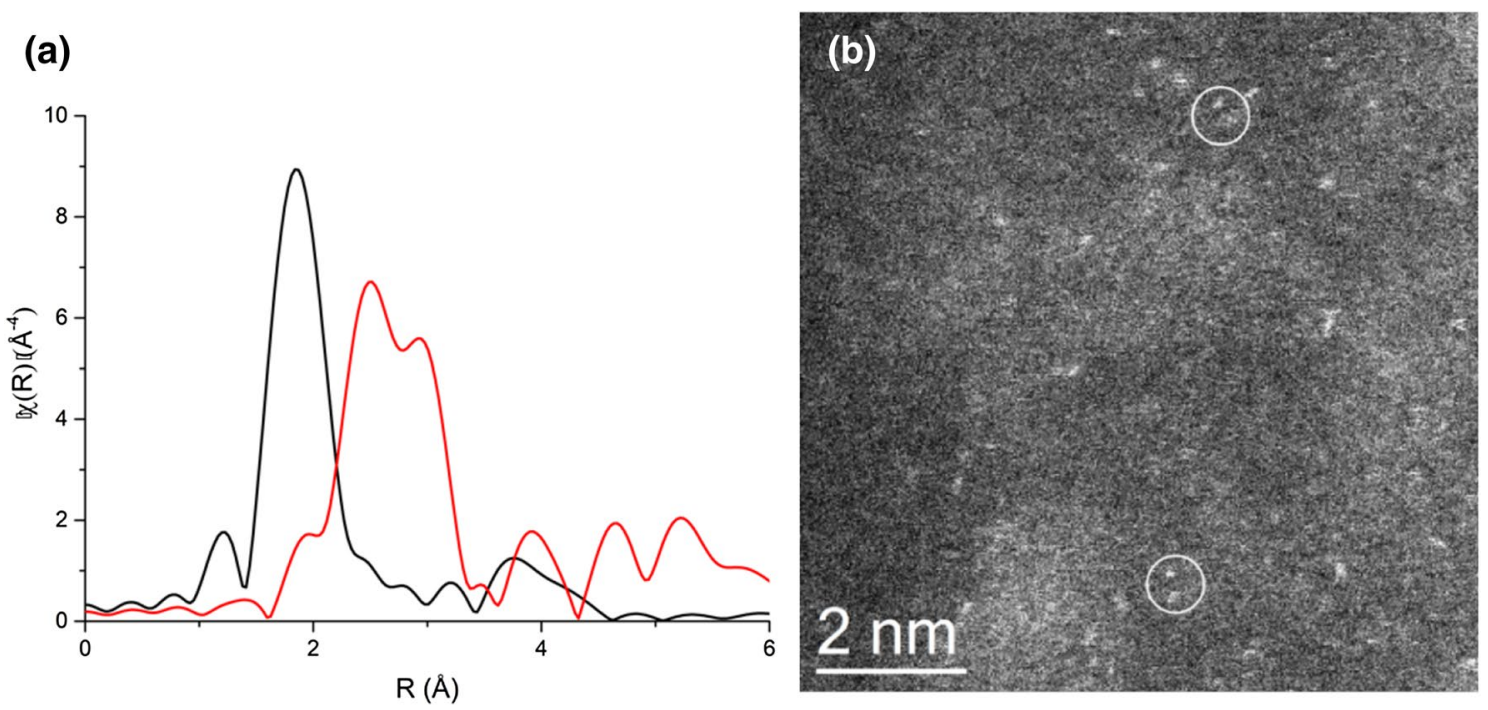

Fig. 4 a EXAFS of fresh $1 \mathrm{wt} \% \mathrm{Au} / \mathrm{C}$ prepared with $\mathrm{HAuCl}_{4} / \mathrm{HCl}+\mathrm{HNO}_{3}$ solution (black line catalyst, red line gold foil). b $\mathrm{HAADF}-\mathrm{STEM}$ of fresh catalyst showing isolated gold species (potential minority dimeric species are circled). Reproduced with permission from [49]

the catalytic cycle. Additional evidence for the importance of $\mathrm{Au}(\mathrm{I})$ species in the reaction could be found from the operando study of the $\mathrm{Au}-\mathrm{S}_{2} \mathrm{O}_{3}$ catalyst, which was found to be stable in the $\mathrm{Au}(\mathrm{I})$ oxidation state under reaction conditions combined with immediate catalytic activity (i.e. no induction period).

As repeatedly asserted throughout this perspectives paper, due to multiple and evolving catalyst speciation, a proportionality between proposed active sites and catalytic activity is required to confidently assign mechanism and active site. Such proportionality was demonstrated, for the proposed $\mathrm{Au}(\mathrm{I})$ site in acetylene hydrochlorination, from the linear correlation of normalised white line height against VCM productivity for the individual catalysts throughout the induction period (Fig. 5b). Further, the observed correlation was found to be comparable for all active catalysts prepared with the chloride or thiosulphate ligands (Fig. 5c). Therefore, all the active catalysts investigated in the study shared a common structure and thus, likely, mechanism, which could be further studied.

Several mechanisms have been proposed for gold acetylene hydrochlorination, with $\mathrm{Au}(\mathrm{III}), \mathrm{Au}(0)$ and $\mathrm{Au}(\mathrm{I})$ each being proposed as active sites. One particular mechanism, which postulated oxidative addition of hydrochloric acid across $\mathrm{Au}(\mathrm{I})$ chloride to give an $\mathrm{Au}(\mathrm{III})$ chloride, followed by acetylene addition and reductive elimination of VCM, had been considered viable; other than for the lack of experimental evidence, at that point, for $\mathrm{Au}(\mathrm{I})$ being present in the active catalysts [69]. The observed correlation of $\mathrm{Au}(\mathrm{I}) \mathrm{Cl}$ with activity in the operando study and that global gold oxidation state remained between (I) and (III) provided evidence for the relevance of $\mathrm{Au}(\mathrm{I})$ chloride in the reaction and suggests that $\mathrm{Au}(\mathrm{III})$ is also involved in the reaction cycle in agreement with the postulated redox mechanism.

The clear proportionality between a spectroscopic feature of a single-site catalyst with catalytic activity during the evolution of a reaction shows that an active site can be identified and counted. However, we must consider that although an active site has been identified, the full reaction mechanism is far from been fully understood. A lot of detail of the gold speciation remains unknown, along with the potential importance and role of the carbon support within the reaction [50]. The cause of dramatic gold oxidation on introduction of the reactant gases and the induction period observed in specific catalysts remains unknown. Also, although the number of $\mathrm{Au}(\mathrm{I})$ chloride sites can be correlated with rate, direct evidence of the redox mechanism remains challenging to observe in a steady state operando study. In general, the catalyst remains in its resting state, thus prior to the rate-limiting step, what would be what is observed under steady state conditions. In this case this would be $\mathrm{Au}(\mathrm{I})$ chloride prior to oxidative addition of hydrochloric acid. Evidence of subsequent steps would require studies away from steady state conditions and cannot be captured in a classical operando experiment. 

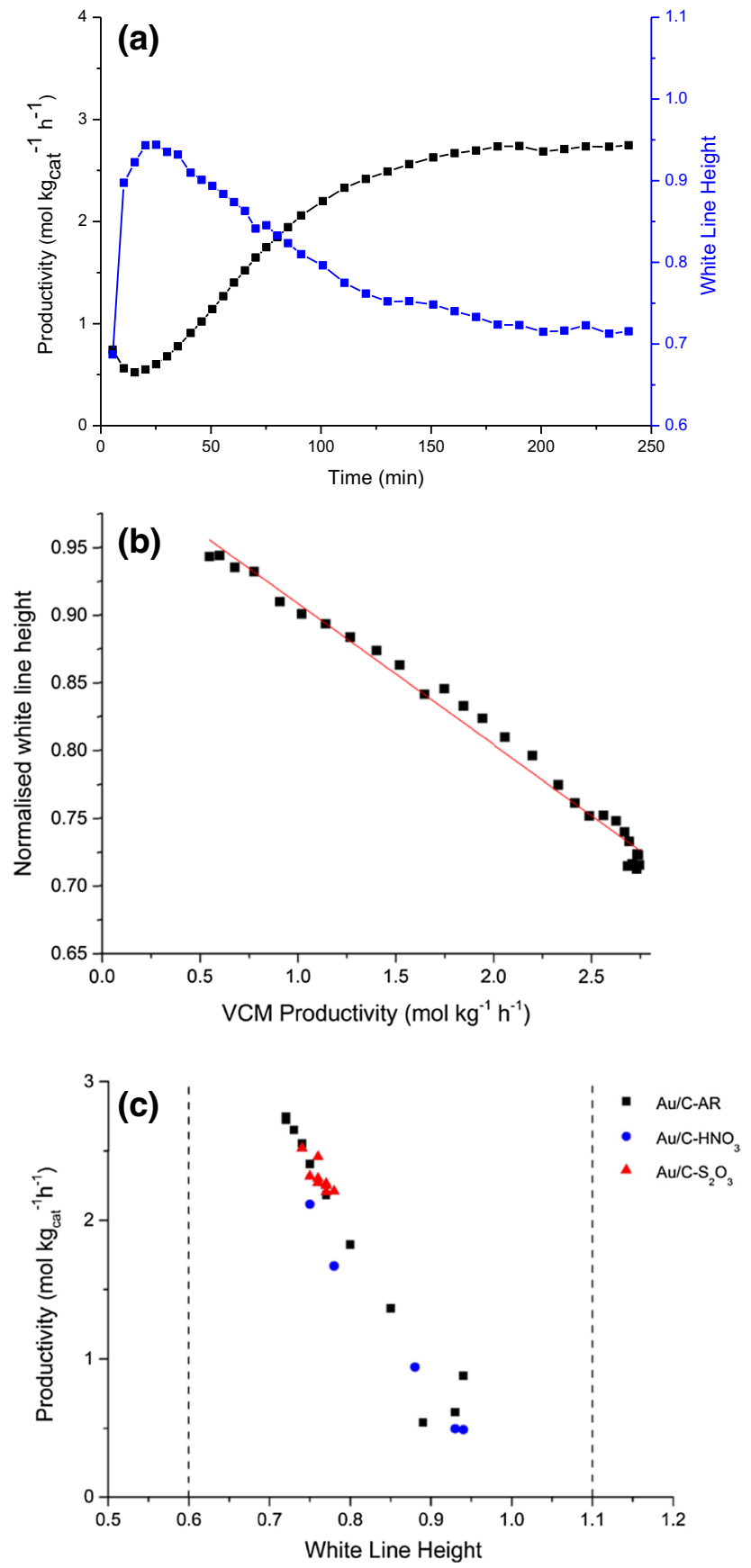

Fig. 5 Correlation between $\mathrm{Au} \mathrm{L}_{3}$ normalised white line and catalytic productivity of $1 \mathrm{wt} \% \mathrm{Au} / \mathrm{C}$ prepared, using excess hydrochloric acid and nitric acid, for the acetylene hydrochlorination reaction. Reaction performed at $200{ }^{\circ} \mathrm{C}$ with $2.36 \%$ acetylene and $2.40 \%$ hydrochloric acid balanced with argon. a Catalyst productivity and corresponding normalised $\mathrm{Au} \mathrm{L}_{3}$ XANES white line height (blue) as a function of time-on-line (black), showing variation of catalytic reactivity and Au oxidation state with time. b Direct comparison of VCM productivity with $\mathrm{Au} \mathrm{L}_{3}$ white line showing proportionality between $\mathrm{Au}(\mathrm{I})$ and catalytic activity. c Comparison of VCM productivity and $\mathrm{Au} \mathrm{L}_{3}$ normalised white line for different catalysts [dotted lines show normalised white line of $\mathrm{Au}(\mathrm{I}) \mathrm{Cl}$ and $\left.\mathrm{Au}(\mathrm{III}) \mathrm{Cl}_{3}\right]$. Reproduced with permission from [49]

\section{Transient Experiments; Correlating Rates of Active Site Transformation and Global Reaction Rates: The Case of Carbon Monoxide Oxidation}

Carbon monoxide oxidation is a much-studied reaction to characterise the structure and activity of catalyst surfaces [70]. It is also a relevant reaction in exhaust gas clean-up and purification of streams of hydrogen. Also, hydrogen for use in PEM fuel cells must contain levels of carbon monoxide below 10 PPM to prevent poisoning of the platinum electrode. One way of doing this is by preferential oxidation: carbon monoxide is oxidized, without reacting hydrogen. Much researched materials for these reactions are noble metals on support, typically alumina and/or ceria, the latter, supported with platinum particles, is discussed here. Ceria is an often-used support, because of its oxygen storage capacity [71]; under oxygen lean conditions, the support provides oxygen thereby reducing $\mathrm{Ce}(\mathrm{IV})$ to $\mathrm{Ce}$ (III). On $\mathrm{Pt} / \mathrm{CeO}_{2}$, carbon monoxide oxidation occurs at the metal-support interface (Fig. 3) and the reaction orders in carbon monoxide and oxygen (both close to zero) suggest non-competitive adsorption on sites that are virtually all covered.

The catalyst described here contains platinum particles of about $1 \mathrm{~nm}$ in diameter that are made by a colloidal method. Under reaction conditions, platinum is fully reduced and fully covered with carbon monoxide, and the discussion here will solely focus on how the structure of cerium changes during one catalytic cycle. In one such cycle, oxygen needs to be dissociatively adsorbed and each atom reacted to adsorbed carbon monoxide. The gas composition is repetitively changed from catalytic (both oxygen and carbon monoxide) to containing only carbon monoxide (Fig. 5). The temperature was varied between 24 and $44{ }^{\circ} \mathrm{C}$ and the conversion was kept below $10 \%$, which ensures constant conditions throughout the whole capillary reactor. Using Ce $2 \mathrm{p}_{3 / 2} 3 \mathrm{~d}_{5 / 2}$ RXES, recorded using a von Hamos detector [72], the cerium oxidation state was determined quantitatively and in a time-resolved manner.

Figure 6 (left panel) shows the that under catalytic conditions at $24{ }^{\circ} \mathrm{C}$, the concentration of $\mathrm{Ce}(\mathrm{III})$ is stabilized at almost two percent, illustrative of the sensitivity of the experiment [73]. Directly after the switch to the feed containing only carbon monoxide, there is first a fast, then a slower increase in $\mathrm{Ce}$ (III) concentration. Because of its oxygen storage capacity, carbon monoxide oxidation continues even in the absence of gas phase oxygen. The rapid switch back to catalytic conditions, causes a very rapid re-oxidation of this formed $\mathrm{Ce}(\mathrm{III})$. The constant concentration of about $2 \% \mathrm{Ce}(\mathrm{III})$ in the operando experiment is not reactive towards oxygen and is therefore not 

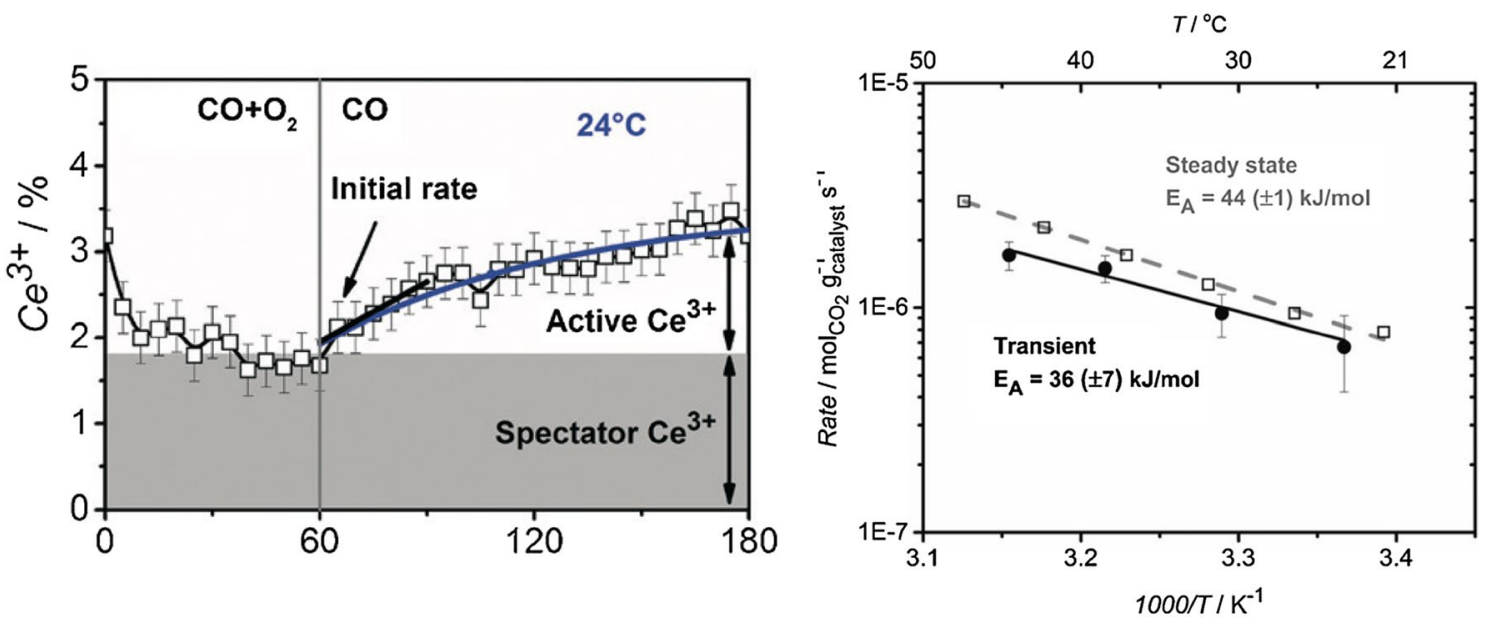

Fig. 6 (Left) Concentration of $\mathrm{Ce}(\mathrm{III})$ in $\mathrm{Pt} / \mathrm{CeO}_{2}$ during a gasswitching experiment. Under catalytic conditions, in carbon monoxide and oxygen, the steady state concentration of $\mathrm{Ce}$ (III) is almost $2 \%$. Directly after switching to a feed containing only carbon mon-

participating in the reaction. The Arrhenius plots (Fig. 6 right panel) of the initial rates of $\mathrm{Ce}$ (III) formation directly after switching off the oxygen component of the feed and of the steady state carbon monoxide oxidation rates are the same within a factor of about 1.5. This similarity indicates that the initial rate of cerium reduction is coupled to the rate-limiting step in the steady state oxidation and forms the basis of the mechanism illustrated in Fig. 3.

The reaction of carbon monoxide with an oxygen atom of the support leads to reduction of two Ce(IV) to two Ce(III). The rate at which this occurs equals the steady state rate of carbon monoxide oxidation. The re-oxidation by oxygen from the gas phase very rapidly re-oxidizes $\mathrm{Ce}$ (III) back to $\mathrm{Ce}(\mathrm{IV})$. Thus, the active cerium atoms are the ones that are reduced directly after the switch from catalytic to carbon monoxide only. Any $\mathrm{Ce}(\mathrm{III})$ that is not changing its oxidation state under either of the two conditions is not involved in the catalytic cycle and is a spectator species. In other words, the $\mathrm{Ce}$ (III) that is observed in the operando experiment is a spectator species. Ce(III) that is part of the catalytic cycle is too short-lived to be detected in the operando experiment. Of course, the (close to) zero order in oxygen indicates that all active sites for oxygen activation are covered, predicting the steady state $\mathrm{Ce}(\mathrm{IV})$ oxidation state.

\section{A Perspective on Counting Catalytic Active Sites and Rates of Reaction}

\subsection{Reaction Kinetics}

The importance of counting active sites and correlating rates associated with these sites by in situ and operando oxide, there is an increase in $\mathrm{Ce}(\mathrm{III})$, faster in the beginning. (Right) Arrhenius plot of the initial rate of $\mathrm{Ce}$ (III) formation (corrected for stoichiometry) and the steady state oxidation rate. Reproduced with permission from ref. [12]

X-ray spectroscopy, towards a fuller understanding of catalytic reaction mechanisms is clear. Such studies are by no means trivial, but when executed correctly, can prevent miss-identification of spectator species as active sites and provide compelling evidence of the correct identification of active species. In both examples, the structure of the catalyst varies with reaction conditions. When this is the case, special care should be given to precisely controlling the conditions under which the experiment is executed. Measuring under conditions that are relevant to actual reaction conditions, such as in an operando and wellexecuted in situ experiment is a necessity. However, both experiments also illustrate that this may be insufficient to identify what is the actual active site. The determination of quantitative correlations is essential. The in situ determination of the number of $\mathrm{Au}(\mathrm{I})$ and its quantitative correlation to the rate of acetylene hydrochlorination gives confidence that this is the actual active species. Such quantitative correlation enables identification of the structure of the active site right before the rate-limiting step.

The example of carbon monoxide over $\mathrm{Pt} / \mathrm{CeO}_{2}$ also illustrates when an operando experiment is insufficient to identify what are the species that participate within a catalytic cycle. Within one catalytic cycle, cerium sequences between oxidation states + III and + IV. As obvious from the (almost) zero order in oxygen, under reaction conditions, the catalyst surface is fully covered in oxygen, thus predicting the cerium + IV oxidation state as resting state within one catalytic cycle. The transient experiment, measuring the kinetics of cerium reduction after switching off the flow of oxygen identified the rate of $\mathrm{Ce}$ (III) to be the same as that of the steady state carbon monoxide oxidation. The much faster re-oxidation to $\mathrm{Ce}(\mathrm{IV})$ causes cerium to be in oxidation state 
+ IV under steady state conditions demonstrating the existence of $\mathrm{Ce}(\mathrm{III})$ spectator species.

As the structure of a catalyst is a function of its precise conditions, in many cases, pre- and post-reaction characterisation does not yield much insight into what is the relevant structure of a catalyst. The interplay between reaction kinetics and characterization in the time domain, under conditions that are relevant to those of the actual catalytic process, may yield the desired quantitative correlation between structure and performance. Understanding of the reaction mechanism by performing reaction kinetics is necessary input for the design of the right experiment. Such insight makes it possible to study the reaction step that affects activity and of course selectivity. One can dissect a catalytic reaction into its fundamental steps of adsorption, (surface) reaction, and desorption, and, for simplicity, assuming Langmuir-Hinshelwood kinetics. The rate- and selectivity-determining steps may be either one of these three and it is very obvious that when one is interested in understanding catalyst performance, it is those steps that should be studied, once again illustrating the importance of reaction kinetics in determining the correct characterisation experiment. Echoing the statement of Bond (in Sec. 1) emphasizing the role of kinetics in assessing the transition state and mechanism, a welcoming advancement is the direct performing of kinetics using one or more of the experimental characterization tools that is or are becoming available. Combining reaction kinetics with structural analysis enables quantifying the relation between the transition state and structure of active site or phase and reactive intermediate.

\subsection{Reactive Materials}

An essential concept when performing in situ and operando studies of catalyst systems is the importance and care required in catalyst preparation. The preparation parameters control the catalyst structure at all length scales. The degree of speciation of different macro- and microstructures within a single sample is an essential factor in determining catalyst performance. On a basic level from a characterisation point of view, it is important to understand catalyst preparation to avoid the presence of preventable spectator species and limit the complexity of broad structural speciation. From a more sophisticated perspective catalyst design can be used pro-actively to prepare model catalysts that maximizes the presence of the proposed active sites, albeit at the expense of practical application or absolute catalytic turnover. While there are many examples of designed model catalysts that have been studied and compared with ex situ characterisation $[4,74,75]$, relatively few have been coupled with operando studies. An excellent example of the latter is the work by Bowker and co-workers who designed core-shell $\mathrm{MoO}_{\mathrm{x}} /$ $\mathrm{Fe}_{2} \mathrm{O}_{3}$ catalysts, where single surface monolayers of $\mathrm{MoO}_{\mathrm{x}}$, proposed as the active species in conventional $\mathrm{Fe}_{2}\left(\mathrm{MoO}_{4}\right)_{3}$, could be studied by XAS without the Mo K edge data being swamped by spectator bulk molybdenum species predominant in $\mathrm{Fe}_{2}\left(\mathrm{MoO}_{4}\right)_{3}$ catalysts [76, 77]. A combination of well-designed operando and transient characterisation experiment coupled with catalyst design is a powerful tool for studying active sites in heterogeneous catalysts.

While single-site catalysts are possibly the best example of having a defined and controlled active site, it should be accepted, and even embraced, that these systems are still quite complex. As discussed (vide supra) and in detail by others [37, 43], there is far more to discover and understand than the simple fact that isolated metal or other potential active site species exist. The role of support interactions, ligands and site coordination, oxidation states and nuclearity should be considered, especially how such parameters alter during reaction. Further it must be demonstrated which highly dispersed species are catalytically active. Again, combination of rational catalyst design, suitable characterisation of species under operation and the demonstration of a proportionality between hypothesised species and reaction rates is required for full understanding. Finally, even if a complete appreciation of a model system has been obtained, this is still not a guarantee that the actual catalyst and process are understood. An interplay between studying model systems and actual catalyst should be an essential ingredient of studies focusing on understanding structure-performance relations in catalytic processes.

Acknowledgements G.J. Hutchings, and members of the UK Catalysis Hub and Cardiff Catalysis institute are thanked for their contribution to the study of gold acetylene hydrochlorination catalysis and related operando studies.

Open Access This article is distributed under the terms of the Creative Commons Attribution 4.0 International License (http://creativeco mmons.org/licenses/by/4.0/), which permits unrestricted use, distribution, and reproduction in any medium, provided you give appropriate credit to the original author(s) and the source, provide a link to the Creative Commons license, and indicate if changes were made.

\section{References}

1. Taylor HS (1925) Proc R Soc Lond A 108:105

2. Templeton DM, Ariese F, Cornelis R, Danielsson LG, Muntau H, Van Leeuwen HP, Lobinski R (2000) PURE Appl Chem 72:1453

3. Somorjai GA, McCrea KR, Zhu J (2002) Top Catal 18:157

4. Vedrine JC (2014) Appl Catal A 474:40

5. Norskov JK, Bligaard T, Hvolbaek B, Abild-Pedersen F, Chorkendorff I, Christensen CH (2008) Chem Soc Rev 37:2163

6. Petrov AW, Ferri D, Krumeich F, Nachtegaal M, van Bokhoven JA, Krocher O (2018) Nat Commun 9:1

7. Hansen PL, Wagner JB, Helveg S, Rostrup-Nielsen JR, Clausen BS, Topsoe H (2002) Science 295:2053

8. Kondrat SA, Smith PJ, Wells PP, Chater PA, Carter JH, Morgan DJ, Fiordaliso EM, Wagner JB, Davies TE, Lu L, Bartley JK, 
Taylor SH, Spencer MS, Kiely CJ, Kelly GJ, Park CW, Rosseinsky MJ, Hutchings GJ (2016) Nature 531:83

9. Grunwaldt J-D, Molenbroek AM, Topsoe N-Y, Topsoe H, Clausen BS (2000) J Catal 194:452

10. Simonsen SB, Chorkendorff I, Dahl S, Skoglundh M, Sehested J, Helveg S (2010) J Am Chem Soc 132:7968

11. Jakubith S, Rotermund HH, Engel W, Von Oertzen A, Ertl G (1990) Phys Rev Lett 65:3013

12. Kopelent R, van Bokhoven JA, Szlachetko J, Edebeli J, Paun C, Nachtegaal M, Safonova OV (2015) Angew Chem Int Ed 54:8728

13. Weckhuysen BM (2003) Phys Chem Chem Phys 5:4351

14. Lamberti C, Zecchina A, Groppo E, Bordiga S (2010) Chem Soc $\operatorname{Rev}$ 39:4951

15. Singh J, Lamberti C, van Bokhoven JA (2010) Chem Soc Rev 39:4754

16. Weckhuysen BM (2002) Chem Commun (Cambridge) 97

17. Bentrup U (2010) Chem Soc Rev 39:4718

18. Fischer N, Clapham B, Feltes T, van Steen E, Claeys M (2014) Angew Chem Int Ed 53:1342

19. Meunier FC (2010) Chem Soc Rev 39:4602

20. Grunwaldt J-D, Caravati M, Hannemann S, Baiker A (2004) Phys Chem Chem Phys 6:3037

21. Goscianska J, Ziolek M, Gibson E, Daturi M (2010) Appl Catal B 97:49

22. Andreeva D, Kantcheva M, Ivanov I, Ilieva L, Sobczak JW, Lisowski W (2010) Catal Today 158:69

23. Burch R, Goguet A, Meunier FC (2011) Appl Catal A 409-410:3

24. Tibiletti D, Meunier FC, Goguet A, Reid D, Burch R, Boaro M, Vicario M, Trovarelli A (2006) J Catal 244:183

25. Signorile M, Crocella V, Damin A, Rossi B, Lamberti C, Bonino F, Bordiga S (2018) J Phys Chem C 122:9021

26. Hammond C, Padovan D, Al-Nayili A, Wells PP, Gibson EK, Dimitratos N (2015) ChemCatChem 7:3322

27. Campbell CT (1994) Top Catal 1:353

28. Campbell CT (2017) ACS Catal 7:2770

29. Filot IAW, Zijlstra B, Broos RJP, Chen W, Pestman R, Hensen EJM (2017) Faraday Discuss 197:153

30. Bond GC (2008) Catal Rev Sci Eng 50:532

31. Bravo-Suarez JJ, Bando KK, Lu J, Haruta M, Fujitani T, Oyama ST (2008) J Phys Chem C 112:1115

32. Iwasawa Y (2003) J Catal 216:165

33. van Bokhoven JA, Lamberti C (2016) X-ray absorption and X-ray emission spectroscopy: theory and applications, vol. 1. Wiley, Chichester)

34. Coperet C, Basset J-M (2007) Adv Synth Catal 349:78

35. Boudart M (1997) J Mol Catal A 120:271

36. Haag WO, Lago RM, Weisz PB (1984) Nature (London) 309:589

37. Gates BC, Flytzani-Stephanopoulos M, Dixon DA, Katz A (2017) Catal Sci Technol 7:4259

38. Flytzani-Stephanopoulos M, Gates BC (2012) Annu Rev Chem Biomol Eng 3:545

39. Thomas JM (2014) Phys Chem Chem Phys 16:7647

40. Thomas JM, Raja R (2006) Top Catal 40:3

41. Wang A, Li J, Zhang T (2018) Nat Rev Chem 2:65

42. Yoo B-K, Su Z, Thomas JM, Zewail AH (2016) Proc Natl Acad Sci USA 113:503

43. Che M, Mori K, Yamashita H (2012) Proc R Soc A 468:2113

44. Hoffman AS, Debefve LM, Zhang S, Perez-Aguilar JE, Conley ET, Justl KR, Arslan I, Dixon DA, Gates BC (2018) ACS Catal $8: 3489$
45. Corma A, Concepcion P, Boronat M, Sabater MJ, Navas J, Yacaman MJ, Larios E, Posadas A, Lopez-Quintela MA, Buceta D, Mendoza E, Guilera G, Mayoral A (2013) Nat Chem 5:775

46. Liu L, Zakharov DN, Arenal R, Concepcion P, Stach EA, Corma A (2018) Nat Commun 9:1

47. Deng W, Frenkel AI, Si R, Flytzani-Stephanopoulos M (2008) J Phys Chem C 112:12834

48. Xiong H, Lin S, Goetze J, Pletcher P, Guo H, Kovarik L, Artyushkova K, Weckhuysen BM, Datye AK (2017) Angew Chem Int Ed 56:8986

49. Malta G, Kondrat SA, Freakley SJ, Davies CJ, Lu L, Dawson S, Thetford A, Gibson EK, Morgan DJ, Jones W, Wells PP, Johnston P, Catlow CRA, Kiely CJ, Hutchings GJ (2017) Science 355:1399

50. Malta G, Freakley SJ, Kondrat SA, Hutchings GJ (2017) Chem. Commun. 53:11733

51. Doornkamp C, Ponec V (2000) J Mol Catal A 162:19

52. Oyama ST, Li W (1999) Top Catal 8:75

53. Braun D (2004) J Polym Sci A 42:578

54. Agnew JB, Shankar HS (1986) Ind Eng Chem Prod Res Dev 25:19

55. Bremer H, Lieske H (1985) Appl Catal 18:191

56. Hutchings GJ, Grady DT (1985) Appl Catal 17:155

57. Hutchings GJ, Grady DT (1985) Appl Catal 16:411

58. Shinoda K (1975) Chem Lett 4:219

59. Hutchings GJ (1985) J Catal 96:292

60. Nkosi B, Coville NJ, Hutchings GJ (1988) Appl Catal 43:33

61. Davies CJ, Miedziak PJ, Brett GL, Hutchings GJ (2016) Chin J Catal 37:1600

62. Hutchings GJ (2014) Top Catal 57:1265

63. Johnston P, Carthey N, Hutchings GJ (2015) J Am Chem Soc 137:14548

64. Nkosi B, Coville NJ, Hutchings GJ, Adams MD, Friedl J, Wagner FE (1991) J Catal 128:366

65. Liu X, Conte M, Elias D, Lu L, Morgan DJ, Freakley SJ, Johnston P, Kiely CJ, Hutchings GJ (2016) Catal Sci Technol 6:5144

66. Conte M, Davies CJ, Morgan DJ, Carley AF, Johnston P, Hutchings GJ (2014) Catal Lett 144:1

67. Fong Y-Y, Visser BR, Gascooke JR, Cowie BCC, Thomsen L, Metha GF, Buntine MA, Harris HH (2011) Langmuir 27:8099

68. Chang S-Y, Uehara A, Booth SG, Ignatyev K, Mosselmans JFW, Dryfe RAW, Schroeder SLM (2015) RSC Adv 5:6912

69. Conte M, Carley AF, Heirene C, Willock DJ, Johnston P, Herzing AA, Kiely CJ, Hutchings GJ (2007) J Catal 250:231

70. Engel T, Ertl G (1979) Adv Catal 28:1

71. Kaspar J, Fornasiero P, Graziani M (1999) Catal Today 50:285

72. Szlachetko J, Nachtegaal M, de Boni E, Willimann M, Safonova O, Sa J, Smolentsev G, Szlachetko M, van Bokhoven JA, Dousse J-C, Hoszowska J, Kayser Y, Jagodzinski P, Bergamaschi A, Schmitt B, David C, Lücke A (2012) Rev Sci Instrum 83:103105

73. Kopelent R, van Bokhoven JA, Nachtegaal M, Szlachetko J, Safonova OV (2016) Phys Chem Chem Phys 18:32486

74. Budroni G, Kondrat SA, Taylor SH, Morgan DJ, Carley AF, Williams PB, Hutchings GJ (2013) Catal. Sci. Technol. 3:2746

75. Volta JC, Portefaix JL (1985) Appl Catal 18:1

76. Brookes C, Wells PP, Dimitratos N, Jones W, Gibson EK, Morgan DJ, Cibin G, Nicklin C, Mora-Fonz D, Scanlon DO, Catlow CRA, Bowker M (2014) J Phys Chem C 118:26155

77. Brookes C, Bowker M, Gibson EK, Gianolio D, Mohammed KMH, Parry S, Rogers SM, Silverwood IP, Wells PP (2016) Catal Sci Technol 6:722 